Faculdade

de Ciências Econômicas UFRGS

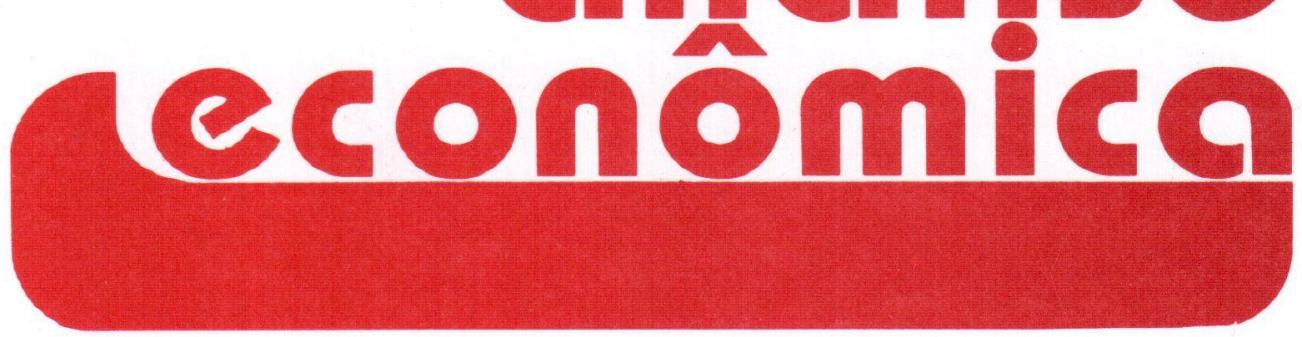

- UM SÉCULOdE INFLAÇÃO: A EVIDÊNCIA EMPÍRICA Fábio Sá Earp

- REGIÕES-CHAVENAINTEGRAÇÃo ECONÔMICA REGIONAL Nali de Jesus de Souza

- THESRAFFIAN INTERPRETATION OF RICARDO: ACRITIQUE José Ricardo Bezerra Nogueira

- QUALIDADE DO MEIO AMBIENTE EFALHAS DE MERCADO

Francisco de Sousa Ramos

- EFEITOS ECONÔMICOS DEESTRATÉGIAS DE PROMOÇÃODE EXPORTAÇÕES Wilson da Cruz Vieira

- "KEYNESIANS", MONETARISTS,NEW CLASSICALS AND NEW KEYNESIANS Fernando Ferrari Filho

- DISTRIBUIÇÃO DA RENDA DO TRABALHO NAINDÚSTRIA BRASILEIRA

Antonio Lisboa Teles da Rosa

- CURSO dE EXTENSÃO EM ECONOMIA PREPARATÓRIO PARA A ANPEC

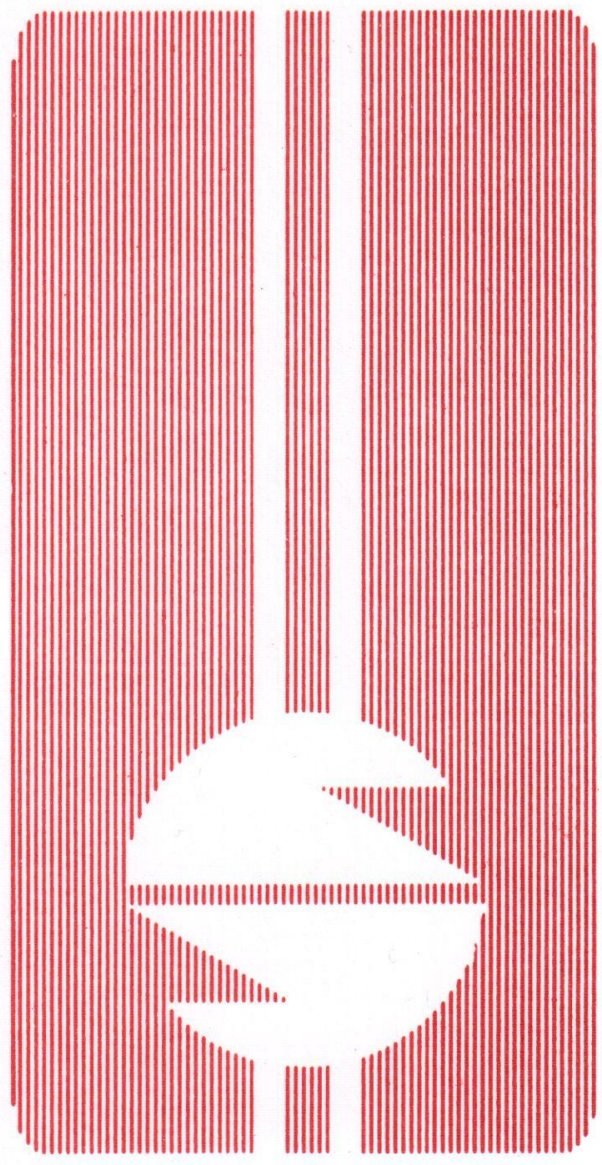


UNIVERSIDADE FEDERAL DO RIO GRANDE DO SUL

Reitor. Prof. Hélgio Henrique Casses Trindade

FACULDADE DE CIÊNCIAS ECONÔMICAS

Diretor. Prof. Pedro Cézar Dutra Fonseca

CENTRO DE ESTUDOS E PEQUISAS ECONÔMICAS

Diretor. Prof. Paulo Alexandre Spohr

DEPARTAMENTO DE CIÊNCIAS ECONÔMICAS

Chefe: Prof. Gentil Corazza

CURSO DE PÓS-GRADUAÇĀO EM ECONOMIA

Coordenador Prof Roberto Camps Moraes

CURSO DE PÓS-GRADUAÇÃO EM ECONOMIA RURAL

Coordenador. Prof. Aray Miguel Feldens

CONSELHO EDITORIAL: Achyles Barcelos da Costa, Aray Miguel Feldens, Atos Freitas Grawunder, Carlos Augusto Crusius, Eugenio Lagemann, Fernando Ferrari Filho, Gentil Corazza, Marcelo Savino Portugal, Maria Imilda da Costa e Silva, Nali de Jesus de Souza, Nuno R. L. de Figueiredo Pinto, Otília Beatriz K Carrion, Paulo Alexandre Spohr, Paulo Dabdab Waquil, Pedro Cezar Dutra Fonseca, Roberto Camps Moraes, Valter José Stulp, David Garlow (Wharton Econometrics Forecasts Association, E.U.A.), Edgar Augusto Lanzer (UFSC), Eleutério F. S. Prado (USP), Fernando de Holanda Barbosa (FGV/RJ), Gustavo Franco (PUC/RJ), JJoão Rogério Sanson (UFSC), Joaquim Pinto de Andrade (UnB), Juan H. Moldau (USP), Werner Baer (Univ de lllinois, E. U.A.).

COMISSÃO EDITORIAL: Fernando Ferrari Filho, Gentil Corazza, Paulo Dabdab Waquil, Marcelo Savino Portugal, Roberto Camps Moraes.

EDITOR: Nali de Jesus de Souza

SECRETARIA Cláudia Porto Silveira, Jeferson Luis Bittencourt e Vanete Ricachescki (revisão de textos).

FUNDADOR: Prof. Antônio Carlos Santos Rosa

Os materiais publicados na revista Análise Econômica são da exclusiva responsabilidade dos autores. É permitida a reprodução total ou parcial dos trabalhos, desde que seja citada a fonte.

Aceita-se permuta com revistas congêneres. Aceitam-se, também, livros para divulgação, elaboração de resenhas e recensões.

Toda correspondência, material para publicação (vide normas na terceira capa), assinaturas e permutas devem ser dirigidos ao seguinte destinatário:

PROF. NALI DE JESUS DE SOUZA

Revista Análise Econômica

Av. João Pessoa, 52

CEP 90040-000 PORTO ALEGRE - RS, BRASIL

Telefones: (051) 316-3348 e 316-3440

Fax: (051) 225-1067 


\section{DISTRIBUIÇÃO DA RENDA DO TRABALHO NA \\ INDÚSTRIA BRASILEIRA: ASPECTOS NACIONAL E REGIONAL*}

Antonio Lisboa Teles da Rosa*

\section{SINOPSE}

O presente estudo analisa a distribuição da renda do trabalho no Brasil, tendo em vista identificar alguns de seus fatores explicativos. É uma análise do tipo cross section para o ano de 1985, utilizando como unidade de observação a industria nacional, desagregada a três digitos Seus resultados são bastante elucidativos e favoráveis à corrente que procura explicar a concentração da renda do trabalho através da segmentação do mercado de trabalho, do diferencial de poder de barganha de cada estrato da classe trabalhadora e das diferenças técnico-estruturais Na comparação regional, salienta-se que o Nordeste apresenta menores niveis de concentração da renda do trabalho, mas também seus salários médios são menores do que a média brasileira. Sendo assim, a menor concentração da renda não representa uma vantagem que os trabalhadores nordestinos têm sobre os das regiões mais industrializadas. Adicionalmente, as estimativas das funções demanda por mão-de-obra indicam que no Nordeste existe um campo bem mais amplo para o crescimento da concentraçäo da renda do trabalho Isto tem como causa o menor nivel quantitativo e qualitativo dos empregos oferecidos no Nordeste e o estágio em que se encontra a sua industria, se comparada à nacional

\section{OBJETIVOS}

Neste estudo analisamos alguns dos fatores explicativos da demanda por mãode-obra nas indústrias brasileira e nordestina. Com isso, procuramos detectar a influência dos aspectos técnico-estruturais e das diferenças no interior da classe trabalhadora que condicionam a distribuição da renda do trabalho, a qual representa uma das faces de um problema mais amplo, que é o perverso quadro de distribuição de renda no País. ${ }^{1}$

Além do mais, é de nosso interesse identificar as diferentes formas de rebatimento do problema a um nivel mais abrangente (nacional) vis-à-vis a um nível mais específico (regional). A escolha do Nordeste decorre da observação de que a região passou por um processo recente de expansão industrial, com tendência à convergência de sua estrutura setorial e tecnológica ao nivel da nacional (Rosa, 1992) No entanto, a região ainda dá sinais de profundas diferenças estruturais e de um quadro de desemprego e subemprego, que se refletem no mercado de trabalho. A partir dessa observação, ganha importância a compreensão do problema ao nível regional. Advertimos que não examinaremos o caso pela óptica da dinâmica da inflação, que se manifesta na interação salários-preços Este enfoque é contemplado em estudos tais como os desenvolvidos por Amadeo e Camargo (1990); Amadeo e Pereira (1990); Marinho (1993), entre outros. Procuramos nos abstrair desta relevante questão e privilegiamos a análise da estrutura da indústria

\footnotetext{
"O autor agradece ao Prof José Jesus de Souza Lemos, do CAEN, pelos seus valiosos comentários, críticas e sugestões; mas desde já, quer isentá-lo dos erros e omissões cometidos.

"Professor adjunto do Curso de Mestrado em Economia da Universidade Federal do Ceará

1 Sobre as diferentes vertentes explicativas da questão, ver Camargo e Giambiagi (1991), Bonelii e Ramos (1993), entre outros
}

\begin{tabular}{|c|l|}
\hline $\begin{array}{c}\text { Cód. AEA } \\
912\end{array}$ & $\begin{array}{l}\text { Palavras-chave: distribuição de renda, estrutura da indústria nacional, função } \\
\text { demanda por mäo-de-obra. }\end{array}$ \\
\hline
\end{tabular}

ANÁLISE ECONŌMICA

ANO 14

Março/ Setembro 96

p. $76-98$ 
nacional, a qual resulta de um processo que comporta as seguintes proposições:

i. o Brasil é um pais de industrialização tardia, a qual traz para o cenário econômico técnicas poupadoras de trabalho. Uma das conseqüências disso é que, ao longo das últimas décadas, o crescimento da produção industrial proporcionou um aumento da demanda por mão-de-obra insuficiente para absorver o crescente contigente populacional urbano, originário do crescimento vegetativo da população e da migração campo-cidade, gerando-se um inquietante quadro de subemprego. Em decorrência disso, possibilitou-se um crescimento da produtividade sem o proporcional repasse para os salários, intensificou-se o quadro concentrador da renda a favor dos lucros e propiciou se a criação de mecanismos de diferenciação entre os trabalhadores, os quais se refletem nas atuais desigualdades de condições de emprego e salários (Ver Souza, 1980, p. 7-114);

ii. a indústria é o setor dinâmico, no qual as transformações ocorrem primeiro e em maior velocidade. ${ }^{2}$ No entanto, sua estrutura não é homogênea, identificando-se setores de mais rápido crescimento, caracterizados pela presença de indústrias de maior tamanho, densidade de capital e de recursos humanos, estrutura de emprego mais hierarquizada, pagam maiores salários etc; ao lado de outros onde é nítida a presença de indústrias de menor tamanho, densidade de capital e recursos humanos, pagam menores salários etc Constatação esta que permite segmentar a indústria em um centro oligopolista, formado pelo primeiro grupo, e uma periferia competitiva, formada pelo segundo (Rosa, 1992);

iii os fatores $i$ e ii interagem, no sentido de facilitar a estratificação da classe trabalhadora em grupos que têm poder de barganha diferenciados, em função do setor onde estão empregados e da posição que ocupam no emprego. Diante disso, podemos classificá-los do seguinte modo a) trabalhadores primários, os quais podem ser desagregados em primários superiores, formados pelos empregados que ocupam cargo de gerência, chefia e supervisão e os de nivel superior, e primários subordinados, os quais congregam os empregados com certo nível de qualificação obtido através de treinamento formal ou no trabalho; e b) trabalhadores secundários, para os quais as exigências em habilidades são mínimas, têm um fraco poder de barganha, as relações de trabalho são instáveis etc. (ver Macedo, 1982; p. $123-167)^{3}$

iv. dado que a inđústria nordestina é mais recente, resultante de um processo de avanço da indústria nacional, no sentido de se beneficiar dos incentivos fiscais, foi fortemente marcada pela implantação de setores mais dinâmicos e com características oligopolistas etc. (A respeito da questão, ver Guimarães, 1989), os fatores $i$, ii e iii também devem estar presentes na indústria da região, porém, com diferenças decorrentes das peculiaridades do seu mercado de trabalho e da vinculação de grande parte das suas unidades produtivas com as matrizes extra-regionais

Nessa perspectiva, em termos mais especificos, pretendemos analisar os efeitos a) das técnicas poupadoras de trabalho; b) da segmentação da indústria; e c) da estratificação dos trabalhadores, nas formas citadas, sobre a distribuição da

\footnotetext{
2 A propósito, ver Rosa (1992, p 56-101), onde é discutida a questāo e ressaltado, inclusive, que a industria brasileira liderou o crescimento econômico e na crise foi o setor mais atingido.

3 Observe que estamos considerando a estratificaçäo em toda a indüstria, no entanto, ela deve se manifestar de uma forma mais nitida no centro oligopolista
} 
renda do trabalho, tanto a nivel nacional, quanto regional. Objetivamos também detectar as diferenças entre o País e uma região em um estágio mais atrasado de desenvolvimento, mas que recebeu um rápido impulso industrial em um passado recente.

\section{HIPÓTESES}

$\mathrm{Na}$ tentativa de alcançar tais objetivos, serão testadas as seguintes hipóteses relativas às indústrias brasileira e nordestina:

H.1- O binômio tecnologia-escala associa-se diretamente à densidade de trabalhadores primários superiores e, portanto, apresenta uma relação positiva com a concentração da renda do trabalho. Dito de outra forma, as indústrias de maior tamanho e que adotam tecnologia mais moderna tendem a gastar mais com os trabalhadores primários superiores, o que torna a renda do trabalho mais concentrada;

H.2- O poder de barganha da classe trabalhadora, na luta pela repartição do produto entre salários e lucros, favorece os trabalhadores primários superiores. Neste caso, quanto maior o poder da classe trabalhadora como um todo de se apropriar de parcela mais significativa do produto, mais forte será o poder dos trabalhadores primários superiores de se apropriarem da renda do trabalho,

H 3- a industria pode ser segmentada em um centro oligopolista e uma periferia competitiva, onde, no centro a renda do trabalho está mais concentrada do que na periferia;

H 4- na comparação regional, o potencial de evolução da concentração da renda do trabalho é mais intenso no Nordeste do que no Brasil, em decorrência da rápida transformação da estrutura da indústria regional a favor de unidades produtivas mais densas em tecnologia, de maior tamanho e pertencentes ao centro oligopolista. Isto reforça mais ainda o processo de segmentação da indústria nordestina, que deve ser mais significativo do que no Brasil.

\section{METODOLOGIA}

Para o teste das hipóteses, estimaremos funções demanda por mão-de-obra, para as regiões em questão, derivadas de uma função custo do trabalho, a qual incorpora a tecnologia, a segmentação da indústria e o poder de barganha dos trabalhadores na repartição do produto entre salários e lucros

A função custo utilizada é que se segue

$$
C T=f\left(r_{1}, Y\right)
$$

onde

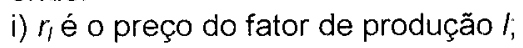

ii) Yé o nível de produto.

Essa função deve ser linearmente homogênea, crescente e côncava nos preços dos fatores e não decrescente em relação ao nivel de produção.

Seguindo os passos de Bartel e Litchenber (1987), consideraremos apenas dois fatores capital e trabalho, dos quais o capital é tratado como um fator quase-fixo. Portanto, os produtores não ajustam tão livremente a combinação dos recursos produtivos, de acordo com as variações em seus preços relativos. Isto é apropriado para especificar uma função custo mais restrita, a qual incorpora apenas os salários como preços dos fatores. 
Prosseguindo na formulação metodológica, consideraremos duas categorias de trabalhadores

i) primários superiores - formados pelos trabalhadores de nível superior, gerentes chefes e supervisores, os quais são considerados como os melhores dotados de recursos humanos; e

ii) primários subordinados e secundários - formados pelos mestres, contramestres e operários

Ademais, não devemos perder de vista que a tecnologia representa um importante elemento de busca de eficiência por parte das empresas. Portanto, para um dado nivel de produção, a tecnologia mais eficiente deve se refletir em menores custos, sendo esta uma relevante variável que deve ser incorporada à função custo

Não menos importante são as imperfeições de mercado causadas pelo poder dos agentes econômicos interferirem nos preços. No caso em consideração, é bastante conhecido o efeito do poder da classe trabalhadora em manter os salários elevados e, por consequência, os custos com mão-de-obra

Pelo exposto, trabalharemos com a seguinte função custo:

$$
C T N=g\left(\stackrel{+}{W}_{1}, \stackrel{+}{W}_{2}, \stackrel{+}{Y}, \bar{K}, \bar{T}, \bar{P}\right)
$$

onde:

i) CTN é o total da folha de pagamentos;

ii) $W_{1}$ é o salário dos trabalhadores primários superiores;

iii) $W_{2}$ é o salário dos empregados primários subordinados e secundários;

iv) $Y$ é o produto,

v) Ké o estoque de capital físico;

vi) $T$ é um índice que avalia o estado da tecnologia; $e$

vii) $P$ é um índice que procura captar o poder de barganha da classe trabalhadora.

Os supra-escritos "+" e "-" em cada variável representam os sinais esperados das respectivas derivadas parciais de primeira ordem.

Por uma questão de conveniência, adotaremos o vetor $X_{j}$, formado por $X_{1}=Y$; $X_{2}=K_{1} X_{3}=T$, e $X_{4}=P$. Neste caso, a equação (2) passa a ser assim representada:

$C T N=g\left(W_{1}, W_{2}, X_{J}\right)$

Considerando que CTN é do tipo trans-log (ver BARBOSA. 1985, 273-310), a equação (3) passa a ser representada pela seguinte expressão

$$
\begin{aligned}
\operatorname{LnCTN}= & a_{0}+a_{1} \operatorname{Ln}\left(W_{1}\right)+a_{2} \operatorname{Ln}\left(W_{2}\right)+1 / 2\left[a_{11}\left(\operatorname{Ln} W_{1}\right)^{2}+a_{12}\left(\operatorname{Ln} W_{1}\right)\left(\operatorname{Ln} W_{2}\right)+\right. \\
& \left.a_{21}\left(\operatorname{Ln} W_{2}\right)\left(\operatorname{Ln} W_{1}\right)+a_{22}\left(\operatorname{Ln} W_{2}\right)^{2}\right]+ \\
& \sum_{j=1}^{4}\left\{b_{j}\left(\operatorname{Ln} X_{j}\right)+1 / 2\left[b_{1 j}\left(\operatorname{Ln} W_{1}\right)\left(\operatorname{Ln} X_{j}\right)+b_{2 j}\left(\operatorname{Ln} W_{2}\right)\left(\operatorname{Ln} X_{j}\right)\right]\right\}+\sum_{i=1}^{4} \sum_{j=1}^{4}\left(c_{i j} Z_{i j}\right)
\end{aligned}
$$

onde:

i) Ln que antecede cada variável representa o logaritmo natural correspondente, e ii) $\sum_{i=1}^{4} \sum_{j=1}^{4}\left(C_{i j} Z_{i j}\right)$ representam as interações e os termos quadráticos de $X_{j}$ 
Uma das consequências da minimização dos custos é que a derivada parcial da equação (4) em relação a $W_{1}$, por exemplo, é igual a: ${ }^{4}$

$$
\delta \operatorname{LnCTN} / \delta \operatorname{Ln}\left(W_{1}\right)=A_{1}
$$

onde

i) $A_{1}$ é a participação dos gastos com mão-de-obra primária superior no total da folha de pagamentos. Quanto maior for seu valor, mais concentrada estará a renda do trabalho nas mãos da categoria 1

A partir de (4) e (5), obtemos a demanda por mão-de-obra primária superior, ou seja

$$
A_{1}=a_{1}+a_{11} L n\left(W_{1} / W_{2}\right)+\sum_{j=1}^{4} b_{i j}\left(\operatorname{Ln} X_{j}\right)
$$

Utilizando as propriedades de homogeneidade linear nos preços dos fatores e a simetria nos parâmetros de interação, podemos escrever a equação (6) da seguinte forma:

$$
A_{1}=a_{1}+a_{11} \operatorname{Ln}\left(W_{1} / W_{2}\right)+\sum_{j=1}^{4} b_{1 j}\left(\operatorname{Ln} X_{j}\right)
$$

Esta é a equação final que queriamos chegar. Observamos que ainda falta uma variável capaz de captar a segmentação da indústria, a qual testará a hipótese $\mathrm{H} 3$

Antes de mais nada, queremos destacar que as unidades de observação utilizadas dizem respeito aos grupos industriais brasileiros e nordestinos, segundo a classificação do IBGE a 3 digitos, a qual abrange até 141 setores, para o ano de 1985, obtidas através de tabulações especiais, junto àquele órgão A partir daí, aqueles setores foram classificados de acordo com o critério da maior produtividade e dos maiores salários, ou seja, os setores que apresentaram produtividade do trabalho e salários médios superiores ao total da indústria foram considerados como pertencentes ao segmento oligopolizado, enquanto os demais ao competitivo. Este critério de escolha resultou em 28 setores pertencentes ao primeiro grupo e 127 ao segundo, cuja especificação encontra-se na Tabela A 1, anexa.

$\mathrm{Na}$ tentativa de encontrar alguma consistência na escolha, aplicamos o teste proposto por Scheffé (ver Goldenberger, p. 1964, 227-231), a fim de verificar se a referida divisão tem aceitação estatística. Os valores da estatística $F$ calculados foram. i) $4.515,26$ para a produtividade e 89,43 para os salários, relativos ao Brasil; e ii) 4054,38 para a produtividade e 254,33 para os salários, relativos ao Nordeste Portanto, rejeitamos a hipótese de igualdade das médias dos grupos a um nível de significância menor do que $1 \%$. Assim, já dispomos de indícios de que os setores com produtividade e salários acima da média da indústria se diferenciam dos demais $^{5}$

A partir dessas colocações, podemos especificar a seguinte regressão a ser estimada para as indústrias brasileira e nordestina.

$$
A_{i 1}=a_{1}+a_{11} L n\left(W_{i 1} / W_{i 2}\right)+b_{11} L n\left(Y_{i}\right)+b_{12} L n K_{i}+b_{13} L n\left(T_{i}\right)+b_{14} L n\left(P_{i}\right)+c D_{i}+u_{i}
$$

\footnotetext{
${ }^{4}$ Ver Barbosa (1985, p 294-296), onde é desenvolvida a demonstração equivalente

Procedimento semelhante foi adotado, com relativo sucesso, por Rosa (1992), para o caso do Brasil, São Paulo, Nordeste, Bahia, Pernambuco e Ceará
} 
As especificações e limitações das respectivas variáveis são as que se seguem:

i) $A_{i 1}$ - gastos com mão-de-obra do tipo $1 \mathrm{em}$ relação ao total da folha de pagamentos, para a indústria $i$ - Esta é uma variável que apresenta poucos problemas técnico-conceituais, uma vez que sua definição se aproxima muito de sua unidade de medida, qual seja: Folha Salarial dos Trabalhadores do Tipo 1/Folha Salarial Total (em \%);

ii) $W_{i 1} W_{i 2}$ - salário relativo da indüstria $i$ - $O$ ideal seria utilizar o salário/hora, 0 qual não se encontra disponível, portanto, consideramos a relação Salário Médio dos Trabalhadores do Tipo 1/Salário Médio dos Trabalhadores do Tipo 2 (em \%), como proxy desta variável;

iii) $Y_{i}$ - produto por estabelecimento da indústria $i$ - Como estamos lidando com setores que congregam diferentes unidades produtivas, o tratamento mais adequado ao caso é através da média de cada indústria. Sendo assim, a unidade de medida utilizada foi Valor da Transformação Industrial/Número de Estabelecimentos (em Cr\$ milhões) Observe que o VTI é uma aproximação do Valor Adicionado e sua magnitude por estabelecimento é um indicador do tamanho médio de cada indústria;

iv) $K_{i}$ - estoque de capital físico de cada setor $i$ - Uma das grandes dificuldades encontradas tem sido adequar o conceito desta variável à sua mensuração. Muitas tentativas foram feitas, emergindo a capacidade instalada em cavalo vapor e o consumo de energia elétrica (Ver Pinheiro, 1991). A vantagem desta segunda variável é que ela capta o grau de utilização da capacidade instalada. No presente estudo adotamos a relação Consumo de Energia Elétrica (em $1000 \mathrm{kw}$ )/Número de Estabelecimentos;

v) $T_{i}$ - índice tecnológico do setor $i$ - Entendemos que a tecnologia está relacionada a novos processos de produção, os quais introduzem a utilização de equipamentos e mão-de-obra de melhor qualidade, portanto mais produtivos

Um dos grandes problemas encontrados em economia é como mensurar a tecnologia e sua contribuição ao produto. Há uma tendência em aceitar que os equipamentos de safra mais recente incorporam processos mais modernos Daí, um indicador tecnológico seria a idade dos bens de produção. No entanto, é de se reconhecer que esta variável ainda está longe de ser avaliada adequadamente.

A qualidade da mão-de-obra, por seu turno, é uma variável que pode apresentar maiores facilidades de tratamento empírico e admite-se, em geral, que há uma associação positiva entre a qualidade do capital e da mão-de-obra, ou seja, o capital que incorpora tecnologia mais moderna exige maior dotação de recursos humanos incorporados ao fator trabalho. Assim, uma indústria mais intensiva em recursos humanos estaria utilizando uma tecnologia mais moderna. Uma forma de mensurar essa variável seria através da proporção de pessoas com mais elevado nivel de instrução formal, em relação ao total de empregados (Indicadores semelhantes a estes encontram-se em Silveira et alii (1983); Pinheiro (1991); Rosa (1992), entre outros)

Os dados disponiveis permitem que utilizemos como proxy desta variável a relação Gerentes, Chefes e Supervisores e Técnicos de Nivel Superior (vezes 1000)/Mestres, Contramestres e Operários. A incorporação dos gerentes, chefes e

\footnotetext{
6 A folha salarial total corresponde às despesas com: i) presidentes e diretores; ii) gerentes, chefes,
} supervisores e pessoal de nivel superior, e iii) mestres, contramestres e operários 
supervisores ao índice de recursos humanos se deve a duas questões a) as informações utilizadas apresentam esta agregação; e b) é de se reconhecer que pessoas que exercem aquelas funções são melhor dotadas em termos de qualificações (uma discussão a este respeito pode ser encontrada em Lanzana, 1987);

vi) $P_{i}$ - índice de poder de barganha dos trabalhadores da indústria $i$, em relação aos empregadores - Esta variável está inserida no rol das que avaliam o poder de monopólio das classes envolvidas na produção. Da parte dos trabalhadores, admitese que há uma relação direta entre o grau de sindicalização e os salários Também é dada ênfase ao grau de monopólio da empresa e proposto que os trabalhadores alocados em empresas mais lucrativas e com maior poder de repassar um aumento de custos para os preços sentem-se encorajados a reivindicar melhorias salariais: Neste caso, os patrões têm mais condições de atender ao pleito e tendem a querer evitar o conflito trabalhista real ou potencial. ${ }^{7}$

Um indicador empregado para mensurar esta variável tem sido a participação dos salários no produto Um bom exemplo deste procedimento pode ser encontrado no trabalho desenvolvido por Kallenberg et alii (1984), no qual é analisado o comportamento da participação dos salários no produto da indústria gráfica norte americana, durante o período 1946-78. Observam os autores que o acréscimo da parcela salarial está associado a um crescimento do poder sindical, enquanto uma redução está associada às mudanças tecnológicas, as quais fortalecem a posição dos empregadores, elevando-se a participação dos lucros no produto.

De um ponto de vista estático, a modificação do poder das classes envolvidas na produção não pode ser avaliada. Mas, podemos considerar que existem diferentes poderes de mercado e heterogeneidade tecnológica envolvendo as diferentes indústrias, onde estão presentes desde oligopólios, até firmas que sobrevivem das sobras do capitalismo competitivo. Portanto, entendemos que uma maior parcela salarial indica uma maior força a favor dos empregados na luta pela repartição do prodûto É uma questão complexa, mas a participação de cada classe na apropriação do produto representa uma síntese que capta as diferenças intersetoriais e de poder

Em razão do exposto, adotaremos a parcela salarial, que será medida pela relação Folha Salarial/Valor da Transformação Industrial (em \%), como proxy da variável em apreciação No entanto, na análise empírica abordaremos uma outra forma de captar o efeito do poder da classe trabalhadora na distribuição da renda do trabalho,

vii) $D_{i}$ - variável binária que assume o valor 1 para as industrias do centro oligopolista e zero para os demais casos, e

viii) $u_{i}$ - termo aleatório, que atende os pressupostos de ser normalmente distribuído, com média zero e variância constante.

De acordo com as proposições feitas, os parâmetros $b_{11}$ e $b_{13}$ associam-se ao teste da hipótese $\mathrm{H} 1$, o $b_{14}$ a $\mathrm{H}_{2}$, e o c a H.3 Caso os respectivos parâmetros sejam significativamente maiores do que zero, aceitamos as hipótese propostas Quanto à hipótese H.4, sua análise será efetuada através da comparação das estimativas da equação (8) para o Brasil e para o Nordeste

\footnotetext{
${ }^{7}$ Devemos observar que, nessas industrias, os trabalhadores auferem remuneração média superior No entanto, o lucro é o limite para tais concessōes
} 


\section{EVIDÊNCIA EMPÍRICA}

\subsection{0 caso brasileiro}

A partir das definições e especificações anteriores, estimamos a equação (8) para a indústria nacional, através do método dos mínimos quadrados ordinários (MQO). As informações utilizadas originaram-se da Tabela A.1, anexa, e os resultados obtidos foram

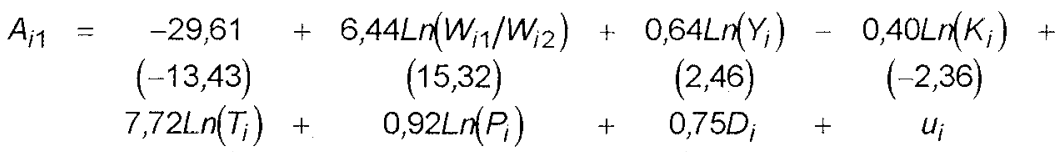

$$
\begin{aligned}
& (24,15) \quad(2,68) \quad(1,65) \\
& R^{2}=0,894 \quad N=137 \quad F=183,24
\end{aligned}
$$

Os valores entre parênteses são as estatisticas $t$ de Student. As estimativas dos parâmetros de cada variável são significativas a menos de $5 \%$. A partir daí, poderemos aceitar as hipóteses H.1 a H.3 para o Brasil, cabendo agora uma análise mais detida sobre o caso ${ }^{8}$

A estimativa do parâmetro relativo à variável $W_{i 1} / W_{i 2}$ apresenta sinal condizente com a idéia de que o maior salário dos trabalhadores primários superiores não acarreta uma proporcional redução de seu emprego. Pelo contrário, está a indicar que a demanda por tal categoria de mão-de-obra é menos elástica em relação aos salários do que a demanda pelos trabalhadores primários subordinados e secundários

Não menos importante foi o tamanho da indústria na determinação de $A_{i}$, pois quanto maior for o tamanho médio dos estabelecimentos, mais expressiva é a necessidade de mão-de-obra confiável para controlar os processos de produção e de trabalho, recaindo sobre aqueles tal responsabilidade, que se traduz em maiores despesas, em relação aos demais empregados.

Um outro destaque observado nos resultados é que o parâmetro relativo a $K_{i}$ é negativo, o que não causa nenhum transtorno à análise, uma vez que não existe uma hipótese definida quanto ao seu sinal Pelo constatado, podemos aceitar que o capital físico, da forma em que é mensurado, é um substituto da mão-de-obra $e$, dados a produção e os salários, seu maior nivel acarreta a necessidade de uma proporção mais elevada de trabalhadores pertencentes ao segmento primário subordinado, manifestando-se isto em uma menor proporção das despesas com trabalhadores primários superiores

\footnotetext{
${ }^{8}$ Vale salientar que, ao analisarmos a possibilidade de correlação forte entre as variáveis explicativas, constatamos que existe alguma dependencia entre $K_{i}$ e $\gamma_{j}$ (o coeficiente de correlação simples entre essas variáveis foi de aproximadamente 0,75 ). Embora esta constatação não seja suficiente, já dispomos de um indício da presença de colinearidade Tentando identificar até que ponto o possivel problema afeta os resultados, estimamos duas novas regressões da equação (8), sendo uma sem a variável $K_{\text {; }}$ e outra sem $Y_{j}$. Os resultados permitiram concluir que as alteraçöes no poder de explicação das demais variâveis sobre $A i$ são de pouca expressão Ademais, a exclusão de $Y_{i}$ manteve a estimativa de $b_{12}$ com o mesmo sinal (negativo), mas só foi significativa a $20 \%$. Por outro lado, a subtração de $K_{i}$ pouco alterou a significância da estimativa de $b_{11}$. Neste caso, se fossemos ignorar alguma variável, o processo de escolha recairia sobre

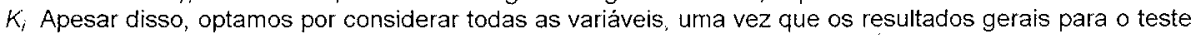
das hipóteses propostas não foram prejudicados.
} 
Já a tecnologia manifesta-se como um outro fator explicativo da maior participação dos trabalhadores primários superiores na folha salarial. Através dela, podemos perceber que, quanto mais densa for a atividade em tecnologia, mais concentrada a renda do trabalho

Este resultado não conflita com o proposto por Langoni (1973), segundo o qual, as atividades mais modernas proporcionam um estímulo adicional à demanda por mão-de-obra do tipo 1 , elevando-se sua remuneração, ao ponto de ampliar $A_{i 1}$. No entanto, a situação seria transitória, uma vez que os salários superiores seriam um estímulo para o investimento em capital humano, o que elevaria a sua oferta. Todavia, a realidade tem dado sinais de que tal reversão encontra sérias dificuldades de se concretizar (Bonelli e Ramos, 1993). Por outro lado, Sabóia (1990) demonstra que a política salarial tem um relevante papel na distribuição da renda do trabalho, o que relativiza o poder explicativo veiculado pelo primeiro autor

A parcela salarial, por sua vez, vem a confirmar que o poder de barganha das diferentes categorias de trabalhadores é heterogêneo Portanto, quanto maior 0 poder daquela classe como um todo em se apropriar do produto, mais expressivo será o poder dos empregados primários superiores em se apropriarem da renda do trabalho

É evidente que essa variável tem limitações de ordem técnica, pois sua magnitude depende também das características do próprio setor Ela seria uma boa proxy para indústrias homogêneas ou para comparações intertemporais, informações estas não disponiveis, pelo menos para o nível de detalhamento proposto. Assim, sua relação com $A_{j}$ pode estar refletindo características estruturais, embora não devamos descartar a sua relação com o poder de barganha dos trabalhadores.

$\mathrm{Na}$ tentativa de contornar tal restrição, procuramos captar a capacidade dos trabalhadores primários superiores se apropriarem de uma maior proporção da renda do trabalho, através da produtividade Para tanto, estimamos a seguinte regressão, através do método dos (MQO)

$$
\begin{gathered}
\operatorname{LnPM_{i}}=\begin{array}{c}
0,564 \\
(1,92)
\end{array} \quad \begin{array}{c}
0,354 \operatorname{Ln}\left(Y_{i}\right) \\
(9,67)
\end{array} \quad \begin{array}{c}
0,237 \operatorname{Ln}\left(T_{i}\right) \\
(3,64)
\end{array} \quad \begin{array}{c}
0,405 D_{i} \\
(4,28)
\end{array}+e_{i} \\
\mathrm{R}^{2}=0,733 \quad \mathrm{~N}=139 \quad \mathrm{~F}=123,36
\end{gathered}
$$

onde

i) $L N P M_{i}$ é o log natural do produto por trabalhador do setor $i$, avaliado pela relação Valor da transformação Industrial (em Cr\$ milhões)/Total de empregados; e

ii) $e_{i}$ é o termo aleatório, com os mesmos pressupostos de $u_{i}$

Através destes resultados, aceitamos que a produtividade do trabalho é explicada pela tecnologia $\left(T_{i}\right)$, tamanho $\left(Y_{i}\right)$ e existem diferenciações setoriais que a torna distinta $\left(D_{i}\right)$ Ora, mas quanto maiores forem os valores observados destas variáveis, maior a produtividade e $A_{i}$ Assim, o repasse dos ganhos de produtividade para os salários se verifica com uma maior absorção da renda do trabalho pelos trabalhadores do tipo $1 \mathrm{Em}$ outras palavras, a produtividade deve manter uma relação direta com a concentração da renda do trabalho. Por esse outro caminho, reforçamos a idéia de que os trabalhadores do tipo 1 têm vantagens, em termos de 
poder de barganha, sobre os demais. ${ }^{9}$

Finalmente, $D_{i}$ apresenta estimativa com o sinal esperado e significativa a menos de $5 \%$. Este resultado é compatível com a hipótese $\mathrm{H} .3$ e indicativo de que existem diferenças setoriais que tornam a renda do trabalho mais concentrada no centro oligopolista. Ora, se relembrarmos a forma de definir este grupo (o qual é formado por setores que apresentam produtividade e salários superiores à média da indústria como um todo) e se considerarmos os resultados de um trabalho anterior (Rosa, 1992) (no qual evidenciamos que os setores de maior produtividade e salários são os de maior tamanho e densidade tecnológica); percebemos que aquelas indústrias caracterizam-se pela presença de um elemento adicional não captado pelas demais variáveis explicativas de $A_{j}$, elemento este que se manifesta em um diferencial de concentração da renda do trabalho a seu favor. Isto está de acordo com a idéia de que indústrias do centro oligopolista apresentam uma estrutura de emprego mais hierarquizada e marcada pela presença de trabalhadores primários superiores.

Em resumo, constatamos que $A_{i}$ é determinada pelo conjunto de variáveis explicativas proposto Sendo assim, o nível de concentração da renda será maior ou menor, de acordo com a magnitude dos parâmetros e dos valores observados relativos àquelas variáveis

Um outro aspecto deste estudo que não pode ser ignorado é que a análise aqui desenvolvida é estática. Todavia, é de extrema importância o entendimento do comportamento de $A_{i}$. Como não dispomos de informações intertemporais, podemos lançar mão do conceito de elasticidade, o qual permite projetar as variações de $A_{i}$, caso ocorram alterações em alguma das variáveis explicativas Este procedimento tem limitações bastante sérias; dentre elas, destacamos a suposição de constância dos parâmetros estimados ao longo do tempo. No entanto, considerando as restrições de informações, é uma maneira razoável de abordar a questão.

Pelo tipo de função estimada, a sensibilidade de $A_{i}$ em relação a modificações em qualquer variável explicativa é representada pela seguinte expressão:

$$
E_{k}=\left(\delta A_{i} / \delta X_{k i}\right) *\left(X_{k i} / A_{i}\right)=\left(a_{k} / A_{i}\right)
$$

onde:

i) $X_{k i}$ é qualquer uma das variáveis independentes; e

ii) $a_{k}$ é o parâmetro estimado correspondente

Neste caso, as elasticidades parciais ou total não são constantes, mas decrescentes. Ou seja, quanto major for $A_{j}$, menor será a sua reação a uma mudança nos valores observados de $X_{k j}$. Desta forma, podemos inferir que $A_{i}$ cresce com o tamanho, a tecnologia etc mas a taxas decrescentes e, a partir de um certo nivel, $A_{i}$ apresenta uma rigidez tal que, na ausência de intervenção no mercado, torna-se mais dificil a renda do trabalho ser redistribuída.

Ademais, as indústrias mais modernas e tendentes à oligopolização apresentam um maior nivel de $A_{i}$ e tendem a conservá-lo, crescendo (decrescendo) pouco na expansão (retração). Por outro lado, as indústrias mais competitivas, ao entrarem em uma fase de expansão, tendem a crescer em tamanho, tecnologia etc., o que

\footnotetext{
9 Devemos ainda salientar que a omissão da variável $P_{\text {; }}$ ainda nos deixa com relevantes fatores explicativos da distribuição da renda do trabalho, tais como a tecnologia, o tamanho e a segmentação, que associam-se às hipóteses $\mathrm{H} 1$ e $\mathrm{H}_{2}$
} 
Thes dá mais poder de estratificar os trabalhadores, promovendo, assim, uma intensificação da concentração da renda do trabalho Dito de outra forma, em uma fase de crescimento (retração) as indústrias que apresentam índices de concentração da renda superiores tendem a estabilizar tal situação, enquanto as de menor índice tendem a ampliá-lo (reduzi-lo)

Finalmente, se quisermos estender este raciocínio para as diferentes regiões brasileiras, é de se esperar que nos centros mais desenvolvidos o nível de concentração da renda esteja mais acentuado, mas nas regiões atrasadas tenda a crescer mais rapidamente. Ora, observando que nos últimos anos a indústria nacional tendeu a se desconcentrar do eixo Rio-São Paulo, é de se esperar que o processo tenha sido acompanhado da intensificação da concentração da renda do trabalho nas regiões menos desenvolvidas Isto corrobora a proposição de intensificação da coricentração da renda no Nordeste brasileiro, por exemplo, pois a desconcentração industrial traz a homogeneização regional da tecnologia e da estrutura de emprego e salários. É o que tentaremos demonstrar a seguir

\subsection{O caso nordestino}

O caso do Nordeste ganha relevância por se tratar de uma região que passou por um recente crescimento e transformações de sua estrutura produtiva, decorrentes dos incentivos fiscais que favoreceram a desconcentração industrial do Sudeste, notadamente de São Paulo, na direção Nordeste, de tal modo que devem ter sido criadas condições propícias ao processo concentrador da renda do trabalho

Os resultados da estimativa da equação (9) para o Nordeste foram os que se seguem, cujas informaçôes utilizadas originaram-se da Tabela A.2, anexa

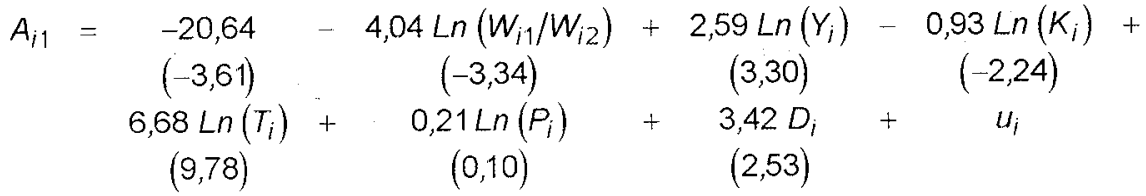

$$
\begin{aligned}
& R^{2}=0,62 \quad \mathrm{~N}=112 \quad \mathrm{~F}=28,10
\end{aligned}
$$

Observamos que a estimativa correspondente a $\left(P_{i}\right)$ não foi significativamente diferente de zero, enquanto as demais o são a menos de $5 \%$ de significância

0 parâmetro estimado, relativo à variável $\left(W_{i l} / W_{i 2}\right)$, apresenta sinal negativo Este resultado indica que os maiores salários dos trabalhadores do tipo 1 associamse a uma proporção menor do seu emprego, em relação aos trabalhadores do tipo 2. Neste caso, para o Nordeste, ao contrário do constatado para o Brasil, a demanda por trabalhadores primários superiores é mais elástica em relação ao salário do que a demanda por trabalhadores primários subordinados e secundários.

Uma provável explicação para isto é o fato de ter se instalado no Nordeste empresas que, em grande parte, são filiais de unidades produtivas de outras regiōes. Ora, as matrizes concentram a maior parte dos trabalhadores estratégicos, ficando nas filiais os trabalhadores primários superiores que têm um menor raio de manobra para tomar decisões Sendo assim, estes não são os que despertam o maior interesse do grupo empresarial em estimulá-los e prestigiá-los. Além do mais, como este tipo de mão-de-obra é muito disputada nas regiões mais desenvolvidas, 
é de se esperar que a sua demanda seja menos elástica ali, uma vez que seu mercado de trabalho está bem melhor estruturado do que em uma região onde aquela categoria de trabalhadores tem uma importância relativa menor

As estimativas dos parâmetros das variáveis tamanho $\left(Y_{i}\right)$ e tecnologia $\left(T_{i}\right)$ apresentam sinais condizentes com a aceitação da hipótese $H 1$. Ou seja, quanto maiores os seus valores, mais concentrada será a renda do trabalho no Nordeste. Vale salientar que a estimativa relativa a $\left(Y_{i}\right)$, para o Nordeste, alcança uma cifra significativamente superior à correspondente para o Brasil, enquanto a relativa a $\left(T_{i}\right)$ ficou em um nivel um pouco inferior.

A variável $\left(K_{i}\right)$, por sua vez, evidencia parâmetro estimado com sinal negativo. Assim, pelas mesmas razões apontadas para o caso brasileiro no item anterior, a densidade de capital fisico está inversamente associada à concentração da renda do trabalho E mais ainda, no Nordeste o fenômeno é mais intenso.

Já a estimativa do parâmetro de $\left(P_{i}\right)$ não foi significativamente diferente de zero, rejeitando-se a hipótese $\mathrm{H} 2$ para o Nordeste. Isto deve estar associado à maior fragilidade relativa do seu mercado de trabalho, que sinaliza com a presença de trabalhadores menos organizados e com menor poder de pressão do que os dos centros mais desenvolvidos

Por fim, o parâmetro relativo a $\left(D_{i}\right)$ apresenta o sinal esperado e demonstra um valor superior ao da mesma variável para o Brasil Com isto, podemos concluir que, no Nordeste, existem diferenças setoriais que contribuem para a concentração da renda do trabalho no segmento oligopolista, de uma forma bem mais intensa do que no País. Em outras palavras, a descontinuidade da função estimada é maior no Nordeste. O resultado vem ao encontro da idéia inicial de que o rápido crescimento da industria regional, direcionado para os setores mais dinâmicos, trouxe como subproduto uma segmentação maior da indústria e a consequente exacerbação da concentração da renda do trabalho

Complementando a análise, foi testada a hipótese de que não existem diferenças entre as duas regressões em comparação, contra a hipótese alternativa de que existem diferenças em, pelo menos, um dos parâmetros $O$ valor da estatística $F(105,130)$ calculado foi 7,72 Portanto, aceita-se a hipótese alternativa a menos de $5 \%$ de significância ${ }^{10}$

De posse desses resultados, e comparando a Tabela A 1 com a Tabela A 2, percebemos que o nivel de concentração da renda do trabalho no Nordeste é superior ao brasileiro em 36 setores, destacando-se ai os mais dinâmicos, para os quais se direcionaram os novos investimentos na Região. Já os setores que menos se expandiram nos últimos anos foram exatamente os que se apresentaram mais defasados tecnologicamente, demonstrando um menor tamanho do que $\mathrm{O}$ correspondente brasileiro (comparar as colunas 2, 3 e 7 da Tabela A 1 com as colunas 1, 2 e 6 da Tabela A 2) e também manifestaram menores niveis de

10 O valor da estatistica $F$ calculado é obtido pela seguinte fórmula

$$
F\left(n_{1}-k ; n_{2}-k\right)=\frac{S Q R_{1} /\left(n_{1}-k\right)}{S Q R_{2} /\left(n_{2}-k\right)}
$$

onde- i) $S Q R_{f}$ e $S Q R_{2}$ säo as somas do quadrado dos erros de estimativa das regressóes 1 (Nordeste) e 2 (Brasil) respectivamente, ii) $n_{1}$ e $n_{2}$ säo o numero de observaçōes das regressões 1 e 2 ; e $k$ é o número de estimadores 
concentração da renda do trabalho

Para a indústria como um todo, no Brasil, $11,5 \%$ da renda do trabalho é apropriada pelos trabalhadores primários superiores, enquanto no Nordeste esta proporção alcança a cifra de $9,7 \%$ Percebe-se, assim, que o nivel médio de concentração da renda do trabalho no Nordeste é menor do que no País Isto se deve à presença de indústrias mais defasadas do que a correspondente nacional, o que se reflete em menores valores para as observações da respectivas variáveis explicativas.

As constatações acima não permitem afirmar que os trabalhadores nordestinos estão em uma siłuação mais favorável $\mathrm{Na}$ verdade, eles auferem, em média, remunerações menores do que os trabalhadores brasileiros, para todas as categorias consideradas neste estudo De fato, em termos agregados, constata-se que i) o salário médio pago aos trabalhadores primários superiores no Brasil é $13,2 \%$ superior ao pago no Nordeste, e ii) os trabalhadores primários subordinados e secundários brasileiros percebem $15,2 \%$ a mais do que os trabalhadores nordestinos.

Finalmente, dos resultados obtidos, concluímos que o potencial de concentração da renda do trabalho do Nordeste é mais intenso do que o do Brasil. Esta conclusão decorre da constatação de que os parâmetros técnico-estruturais $\left(Y_{i}\right.$ e $\left.D_{i}\right)$ são maiores (apenas o correspondente a $T_{i}$ foi um pouco menor), enquanto os niveis dos valores observados das variáveis explicativas são menores. Ora, como estamos tratando de funções cuja variável dependente $A_{i 1}$ apresenta elasticidade decrescente em relação às independentes, a conjunção dos maiores parâmetros com os menores niveis de concentração da renda do trabalho nos leva a aceitar tal proposição. Com isto, aceitamos parcialmente a hipótese $\mathrm{H} .4$

\section{CONSIDERAÇÕES FINAIS}

Da análise elaborada, podemos concluir que a tecnologia, o tamanho e o poder de barganha da classe trabalhadora não são neutros em relação aos próprios empregados e tendem a apresentar diferenciações internas que se manifestam na concentração da renda do trabalho. Adicionalmente, as características da própria industria tendem a fortalecer a divisão interna dos trabalhadores e a criarem uma certa rigidez, que mantém elevados os níveis de concentração da parte do produto destinada a remunerar os empregados Uma das consequêencias do exposto é o comprometimento da expectativa de que o próprio mercado estabeleça mecanismos de ajuste, nos moldes propostos por Langoni e seus seguidores, capazes de corrigir o problema Portanto, a política de fazer "crescer o bolo" para depois distribuí-lo, adotada no passado, e da ausência de intervenção no mercado de trabalho não estimulam a redistribuição da renda.

Estes resultados se revestem de importância quando os associamos aos de um estudo anterior (Rosa, 1992), no qual inferimos que as indústrias de maior tamanho e tecnologicamente mais avançadas são as que conseguem obter maior produtividade, pagam maiores salários e, mesmo assim, são as que mais concentram a renda em favor dos lucros. Portanto, estamos diante de um fenômeno que tem origem mais ampla, qual seja: "as imperfeições de mercado tendem a gerar desigualdades entre as classes (empregadores e trabalhadores) e dentro das próprias classes (centro oligopolista e periferia competitiva, trabalhadores primários e secundários etc), que alimentam o processo de concentração de renda". 
No caso particular da estratificação dos empregados, deparamo-nos com uma situação em que há um comprometimento das partes (empregadores e trabalhadores primários superiores), no sentido de garantir remunerações maiores, em troca da solidariedade de um grupo que é estratégico para o bom desempenho da empresa no longo prazo. É um estado de coisas em que a iniciativa das classes envolvidas é no sentido de preservá-lo. Tais conclusões são válidas para o Brasil e para o Nordeste. No entanto, quando comparamos a Região com o País, concluimos que existem diferenças que denotam particularidades que merecem ser ressaltadas. No caso do Nordeste, há uma evidente caracterização da maior concentração da renda do trabalho nos setores de crescimento recente mais intenso, enquanto os menos dinâmicos demonstram menores niveis salariais e uma renda menos concentrada. Daí, podemos admitir que os setores de mais rápido crescimento introduzem novos processos de produção, que exigem uma despesa com mão-de-obra primária superior proporcionalmente maior do que a requerida com os demais tipos de trabalhadores Isto está associado às mudanças nos indicadores tecnológicos e tamanho que se relacionam diretamente ao nivel de concentração da renda do trabalho.

Um elemento adicional na explicação do fenômeno é a magnitude dos parâmetros estimados, que apresentam valores maiores para o Nordeste. No entanto, não é só a magnitude dos parâmetros que determina o maior potencial de concentração da renda do trabalho no Nordeste Como os niveis observados para as variáveis tamanho e tecnologia, relativos aos setores de menor crescimento, encontram-se abaixo dos mesmos setores ao nivel nacional, constatamos que, na região Nordeste, a elasticidade de $A_{1}$, em ralação àquelas variáveis, é superior à brasileira

A partir daí, podemos inferir que em uma fase de expansão, o processo de concentração da renda do trabalho se amplia, porém com mais intensidade no Nordeste. Destes resultados podemos ainda lançar questões bastante interessantes, por exemplo

i) se há uma associação positiva entre as variáveis técnico-estruturais e a concentração da renda, e, no crescimento, elas se expandem mais exatamente nos setores que mais crescem, então, o processo de crescimento, por si só, nos moldes em que foi adotado no Brasil, é concentrador?

ii) se assim for, que elementos de conflito pela repartição do produto estão aí envolvidos?

iii) como a crise que se abateu durante a década de 80 e se prolongou nos primeiros anos da década de 90 se refletiu no fenômeno?

iv) tivemos aí um processo desconcentrador da renda do trabalho? Se ocorreu isto, o processo foi vantajoso para alguém?

Sobre a questão, queremos adiantar que entendemos que a análise aqui feita é parcial e não contempla toda a problemática do conflito distributivo Todavia, admitimos que os empregadores têm como instrumento de poder a adoção de novas tecnologias, que é mais apropriada em periodos de crescimento suficientes para implantar novas unidades produtivas ou modernizar as existentes Neste caso, no crescimento todos os agentes ganham mais (crescem os lucros e crescem os salários reais dos trabalhadores do tipo 1 e do tipo 2). No entanto, são criadas condições para que os rendimentos dos que detêm maior poder de barganha 
cresçam mais do que os rendimentos dos demais Sendo assim, no crescimento, eleva-se a produtividade mais do que os salários, e os salários dos trabalhadores do tipo 1 crescem mais do que os do tipo 2. Como é uma situação de melhoria para todos, o conflito não se acirra e pouco se manifesta.

No entanto, em uma situação de estagnação e crise como a que se abateu no Brasil nos últimos anos, as possibilidades de aumento de produtividade, sem o proporcional repasse para os salários, se restringem e, ao contrário, os empregadores, para manterem seus níveis de lucro, tendem a pressionar os preços para cima, sendo o fenômeno mais eficaz para os empresários do setor mais oligopolizado. Forma-se, assim, um novo processo de concentração setorial da renda Antes, ela se concentrava a favor de quem crescia mais rápido, agora, a favor de quem tem maior poder oligopolístico.

Por outro lado, os trabalhadores querendo manter seus níveis de renda, pressionam por reposição salarial. Os trabalhadores empregados no centro oligopolista tendem a conseguir repor as perdas em uma proporção maior do que os empregados na periferia competitiva (Marinho, 1993). Desencadeiam-se, desse modo, forças que atuam no sentido de concentrar a renda do trabalho. ${ }^{11}$

Neste caso, em um longo período de crise como o observado a nivel nacional, deparamonos com duas tendências opostas, quais sejam

i) a redução da produtividade (ou estagnação) que contém mecanismos desconcentradores da renda, em decorrência do amortecimento do poder dos empregadores de se apropriarem de uma proporção maior do produto [Amadeo e Pereira, (1990), apresentam evidências nesse sentido]; $\mathrm{e}$

ii) a recessão aumenta a disposição para a luta pela manutenção dos níveis de renda, o que desencadeia o acirramento do conflito distributivo. Desta forma, os segmentos e os estratos que têm maior poder tendem a se apropriarem de maior proporção da renda.

O resultado líquido de todo isto vai depender de qual das forças predomina Portanto, poderemos perfeitamente nos deparar com uma situação de crescimento com concentração da renda (funcional e do trabalho), o que é mais comum no Brasil. Enquanto na recessäo poderemos conviver com uma situação de desconcentração da renda, caso predomine a redução do poder dos empregadores ou dos trabalhadores do tipo 1, ou com uma situação concentradora, caso predomine o poder do centro oligopolista ou dos trabalhadores do tipo 1

Diante do exposto, a solução para o problema de uma melhor distribuição da renda do trabalho no Brasil (e no Nordeste) é uma questão complexa e que exige um entendimento mais amplo do problema. Por outro lado, em uma fase recessiva são criados mecanismos que poderão até contribuir para uma melhor distribuição da renda. No entanto não é esta uma situação desejável, uma vez que se trata de distribuição com piora para todos. Em uma fase de crescimento, geram-se condições de melhoria geral, porém intensificam-se os mecanismos concentradores.

Neste caso, como caminho mais claro que visłumbramos para uma situação desejável é o crescimento acompanhado do fortalecimento do poder sindical dos trabalhadores do tipo 2 e de uma política salarial que procure proteger o poder de compra dos menores salários. Também, seria de bom alvitre a adoção de políticas de redução dos custos dos bens salariais, tais como a diminuição dos impostos que incidem

\footnotetext{
1 Devemos ressaltar que, além desses elementos, existe ainda a intervenção do Governo, estabelecendo políticas de reajuste salarial, que podem amortecer ou não a concentração da renda do trabalho Uma forma de acionar mecanismos desconcentradores seria a proteção do poder de compra dos menores salários
} 
sobre aqueles produtos, por exemplo, bem como uma maior participação de todos os trabalhadores, notadamente os do tipo 2, nos lucros das empresas Estas proposições não conflitam com o proposto por autores, tais como Sabóia (1990) e Marinho (1993). No entanto, o caso é aqui visto como um problema que depende da retomada do crescimento, problema de difícil solução no momento.

\section{ANEXO ESTATISTIICO}

Tabela A.1 - Brasil: Indicadores industriais - 1985

\begin{tabular}{|c|c|c|c|c|c|c|c|}
\hline Setores da Indústria ${ }^{(1)}$ & $\operatorname{Ln}\left(P M_{i}\right)$ & $\operatorname{Ln}\left(Y_{i}\right)$ & $A_{i}$ & $\operatorname{Ln}\left(W_{i 1} / W_{i 2}\right)$ & $\operatorname{Ln}\left(K_{i}\right)$ & $\operatorname{Ln}\left(P_{i}\right)$ & $\operatorname{Ln}\left(T_{i}\right)$ \\
\hline $001^{(2)}$ & 5337 & 10.411 & 17.247 & 1.338 & 9.202 & 2220 & 4.001 \\
\hline 002 & 4243 & 7.505 & 9.527 & 1.303 & 6.497 & 2.852 & 3.354 \\
\hline $003^{(2)}$ & 7.085 & 13.272 & 13149 & 0.912 & 9686 & 0.966 & 4.108 \\
\hline 101 & 3.927 & 7.115 & 5.056 & 0.862 & 5.552 & 2.864 & 3.113 \\
\hline 102 & 4.188 & 7.675 & 7.185 & 1279 & 6.440 & 2.709 & 3.070 \\
\hline 104 & 3.852 & 7.963 & 8.484 & 1382 & 6.606 & 3.001 & 3.147 \\
\hline $105^{(2)}$ & 5.896 & 10.884 & 12.791 & 1.196 & 10.232 & 1.574 & 3.792 \\
\hline 106 & 4.198 & 7.539 & 7.252 & 1.147 & 4.887 & 2719 & 3.212 \\
\hline $107^{(2)}$ & 4.803 & 9.686 & 9.724 & 0.969 & 8.215 & 2.761 & 3.711 \\
\hline 108 & 4.621 & 8.211 & 9.914 & 1.314 & 7.122 & 2311 & 3387 \\
\hline 109 & 4.755 & 8.948 & 17.567 & 1.264 & 6.981 & 2614 & 4.100 \\
\hline $110^{(2)}$ & 5.195 & 10.190 & 13.369 & 1.098 & 9.284 & 2.435 & 3941 \\
\hline $111^{(2)}$ & 5.148 & 9547 & 10.991 & 1.102 & 9.675 & 2.456 & 3.714 \\
\hline 112 & 4.565 & 9998 & 10.159 & 0.704 & 9.467 & 3.319 & 4.024 \\
\hline 113 & 4203 & 8083 & 13054 & 1.144 & 5.527 & 3.010 & 3.868 \\
\hline 114 & 4435 & 8400 & 9768 & 1.055 & 6.101 & 2.943 & 3.629 \\
\hline 115 & 4.278 & 8.672 & 8.742 & 1.151 & 6.505 & 3.107 & 3.411 \\
\hline 116 & 4.160 & 7560 & 8.554 & 1.039 & 5.098 & 2910 & 3499 \\
\hline 117 & 4.610 & 8.709 & 8.776 & 1389 & 6.211 & 2697 & 3.179 \\
\hline 118 & 4.062 & 7.523 & 8.574 & 0.865 & 6.375 & 3258 & 3.676 \\
\hline 119 & 4.553 & 8254 & 11.304 & 1.255 & 6.338 & 2768 & 3.593 \\
\hline $121^{(2)}$ & 4.831 & 9.219 & 13.575 & 0.983 & 6.312 & 2941 & 4.074 \\
\hline 122 & 4.597 & 8.805 & 11800 & 1.007 & 5.549 & 3.037 & 3.889 \\
\hline 123 & 4.585 & 8.770 & 13.391 & 0.886 & 5908 & 3286 & 4.155 \\
\hline 124 & 4.697 & 8.973 & 10.213 & 1.010 & 5.861 & 2.702 & 3.724 \\
\hline 125 & 4.773 & 9.284 & 13.395 & 1.045 & 6.523 & 2848 & 3.996 \\
\hline 126 & 4.859 & 9.857 & 10.908 & 1.420 & 5.959 & 2011 & 3387 \\
\hline $127^{(2)}$ & 4.989 & 9.986 & 17.828 & 0.958 & 7.140 & 2.709 & 4.422 \\
\hline 128 & 3.903 & 8.100 & 12.066 & 0.847 & 6.544 & 3.910 & 4.074 \\
\hline $129^{(2)}$ & 5.298 & 11.522 & 13.782 & 0.896 & 7.915 & 2665 & 4.179 \\
\hline 131 & 4.765 & 9.280 & 16253 & 1.037 & 6.109 & 2834 & 4.231 \\
\hline 132 & 4.840 & 9.288 & 13.063 & 1.050 & 6.764 & 2.655 & 3.962 \\
\hline 133 & 4.667 & 9.728 & 16.590 & 1.421 & 6.834 & 2.699 & 3.872 \\
\hline 134 & 4.629 & 9.666 & 13.507 & 1.079 & 7.070 & 2861 & 3.972 \\
\hline 135 & 4.706 & 9.113 & 10.635 & 1.269 & 5.844 & 2.831 & 3.510 \\
\hline 136 & 4652 & 9.719 & 17.560 & 1.290 & 7037 & 2852 & 4.071 \\
\hline $137^{(2)}$ & 5.464 & 9.847 & 28.461 & 0800 & 5286 & 2463 & 5.186 \\
\hline $138^{(2)}$ & 5.087 & 10.069 & 13.824 & 1.313 & 5817 & 2400 & 3.765 \\
\hline 139 & 4.428 & 7.899 & 14.681 & 0.363 & 4.414 & 3.561 & 4.785 \\
\hline 141 & 4.448 & 8893 & 14.531 & 0.971 & 5.940 & 3.039 & 4.165 \\
\hline 142 & 4.442 & 9.743 & 9435 & 1.186 & 6.968 & 3.469 & 3460 \\
\hline $143^{(2)}$ & 4.879 & 10.009 & 11.263 & 1.072 & 7.592 & 2889 & 3.771 \\
\hline 144 & 4.271 & 8.565 & 9.852 & 1.301 & 5.393 & 3081 & 3.393 \\
\hline 145 & 4.761 & 9.722 & 10.256 & 1.429 & 6.830 & 2.317 & 3.310 \\
\hline
\end{tabular}


Tabela A 1 - Brasil: Indicadores industriais - 1985

\begin{tabular}{|c|c|c|c|c|c|c|c|}
\hline Setores da Indústria ${ }^{(1)}$ & $\operatorname{Ln}\left(P M_{i}\right)$ & $\operatorname{Ln}\left(Y_{i}\right)$ & $\bar{A}_{i}$ & $\operatorname{Ln}\left(W_{i 1} / W_{i 2}\right)$ & $\operatorname{Ln}\left(K_{i}\right)$ & $\operatorname{Ln}\left(P_{i}\right)$ & $\operatorname{Ln}\left(T_{i}\right)$ \\
\hline 147 & 4.825 & 10262 & 18.952 & 0.280 & 6744 & 3.434 & 5174 \\
\hline 148 & 4.176 & 8.195 & 8.542 & 0.860 & 5.070 & 2.987 & 3.677 \\
\hline 149 & 4.035 & 9235 & 3.754 & 0.940 & 6.839 & 3.515 & 2.723 \\
\hline 151 & 3.704 & 6.955 & 4.054 & 0.976 & 4.599 & 2.797 & 2.767 \\
\hline 152 & 3.595 & 6.841 & 4.268 & $0: 862$ & 4.492 & 3.181 & 2.905 \\
\hline 153 & 4.289 & 9.317 & 5.783 & 1413 & 7.962 & 2.479 & 2.704 \\
\hline 154 & 3.581 & 7.035 & 5.041 & 0.364 & 4.578 & 2.952 & 3.608 \\
\hline 155 & 3601 & 7.299 & 4.710 & 1.244 & 5.089 & 3.053 & 2657 \\
\hline 156 & 3.347 & 5.642 & & & 2.300 & 3.184 & - \\
\hline 157 & 4.390 & 7.460 & 8.680 & 1.091 & 4.524 & 2.584 & 3.463 \\
\hline 158 & 3400 & 6.235 & 5489 & 1.410 & 2061 & 2905 & 2.652 \\
\hline 161 & 3.715 & 7.317 & 4.989 & 0.981 & 4619 & 2985 & 2980 \\
\hline 162 & 4.143 & 7.982 & 8.657 & 1.072 & 5.037 & 2.870 & 3.479 \\
\hline 163 & 3.638 & 7344 & 28.582 & 2.323 & 4.735 & 3.414 & 3.669 \\
\hline 164 & 4.681 & 8.418 & 4.345 & 0.597 & 4396 & 2209 & 3.219 \\
\hline 169 & 3.900 & 8.028 & 7.274 & 0.904 & 6.429 & 3.288 & 3.458 \\
\hline $171^{(2)}$ & 5.407 & 9.834 & 10.005 & 1.140 & 8.634 & 2.376 & 3.571 \\
\hline $172^{(2)}$ & 4.968 & 9.954 & 6.323 & 0.925 & 9.269 & 2.561 & 3.287 \\
\hline 173 & 4.788 & 8.798 & 11.418 & - & 6.543 & 2527 & 3.888 \\
\hline 174 & 4.356 & 8.490 & 8.787 & 1.169 & 5501 & 2.812 & 3.399 \\
\hline $175^{(2)}$ & 5.030 & 8.887 & 16.437 & 1.260 & 6.968 & 2.495 & 4.022 \\
\hline 179 & 4.387 & 7.674 & 7.768 & 1486 & 5.567 & 2.427 & 2.947 \\
\hline $181^{(2)}$ & 4.934 & 8630 & 15.407 & 1.347 & 6.769 & 3.248 & 3.858 \\
\hline $182^{(2)}$ & 5.417 & 9.228 & 13.476 & 1.037 & 7049 & 2.384 & 4.011 \\
\hline 183 & 4.573 & 9.168 & 7.211 & 1219 & 6.872 & 2.662 & 3.134 \\
\hline 184 & 3.862 & 8.275 & 0.773 & -0.045 & 6.165 & 3.094 & 2.097 \\
\hline 185 & 4.430 & 8.850 & 12.907 & 1.366 & 6.403 & 2.870 & 3.632 \\
\hline 189 & 4.372 & 8.536 & 3288 & 0.007 & 6.580 & 2.727 & 3.519 \\
\hline 191 & 4.223 & 8.614 & 8.212 & 1.438 & 6.204 & 2.699 & 3.056 \\
\hline 192 & 4.044 & 6.664 & 3.654 & 0.192 & 3.055 & 2.851 & 3.443 \\
\hline 193 & 3.851 & 8301 & 3.303 & 1092 & 4826 & 2.700 & 2.439 \\
\hline 199 & 3.366 & 7.770 & 7.417 & 1384 & 4553 & 3.275 & 2999 \\
\hline $200^{(2)}$ & 5.381 & 9.863 & 14.255 & 1.161 & 9.368 & 2.064 & 3.953 \\
\hline $201^{(2)}$ & 7.078 & 11.808 & 19.409 & 0.771 & 9.809 & 1.350 & 4713 \\
\hline $202^{(2)}$ & 5.835 & 10.506 & 15.050 & 0.703 & 9.196 & 2.150 & 4.474 \\
\hline 203 & 4.201 & 9.387 & 20.770 & 1.462 & 6.709 & 2.927 & 4107 \\
\hline $205^{(2)}$ & 6450 & 10.505 & 18.936 & 0.996 & 5.859 & 1.523 & 4458 \\
\hline $206^{(2)}$ & 6.168 & 9818 & 15.559 & 1.210 & 6.206 & 1.364 & 4.007 \\
\hline $207^{(2)}$ & 5489 & 9.467 & 15.293 & 0.972 & 6.558 & 2.213 & 4.224 \\
\hline $208^{(2)}$ & 5.589 & 9.637 & 12875 & 0.966 & 7.506 & 2.060 & 4.030 \\
\hline $209^{(2)}$ & 5.254 & 8.888 & 17.919 & 1.103 & 4.518 & 2353 & 4.283 \\
\hline $211^{(2)}$ & 5.524 & 9.782 & 18204 & 0.964 & 6704 & 2080 & 4.301 \\
\hline 221 & 5.233 & 9.256 & 17.253 & 1028 & 6.859 & 2.020 & 4.312 \\
\hline 222 & 4.883 & 8.412 & 16.926 & 1169 & 5.845 & 2.375 & 4.148 \\
\hline 223 & 3.894 & 6.797 & 6211 & 1.368 & 3432 & 2.742 & 2.825 \\
\hline 231 & 4.847 & 8.897 & 10.949 & 1.210 & 7.135 & 2.501 & 3.602 \\
\hline 232 & 4.172 & 8.501 & 9.992 & 1.096 & 6.375 & 3.006 & 3.614 \\
\hline 233 & 4.327 & 8.384 & 8.525 & 1288 & 6474 & 2527 & 3247 \\
\hline 235 & 4.261 & 8.322 & 8.706 & 1.161 & 6.540 & 2.762 & 3396 \\
\hline 236 & 5161 & 9443 & 9.319 & 0.987 & 7221 & 2.047 & 3.646 \\
\hline 237 & 4.064 & 7.149 & 2.860 & 1.546 & 5.348 & 3.019 & 1.837 \\
\hline
\end{tabular}


Tabela A 1 - Brasil: Indicadores industriais - 1985

(conclusão)

\begin{tabular}{|c|c|c|c|c|c|c|c|}
\hline Setores da indústria (1) & $\operatorname{Ln}\left(P M_{i}\right)$ & $\operatorname{Ln}\left(Y_{i}\right)$ & $A_{i}$ & $L n\left(W_{i 1} / W_{i 2}\right)$ & $\operatorname{Ln}\left(K_{i}\right)$ & $L n\left(P_{i}\right)$ & $\operatorname{Ln}\left(T_{i}\right)$ \\
\hline 239 & 4.074 & 7.703 & 7.193 & 1.132 & 5.365 & 2.852 & 3.218 \\
\hline 241 & 4.874 & 8.453 & 6.281 & 0.844 & 5.988 & 5.988 & 2.038 \\
\hline 242 & 4.469 & 9433 & 6.042 & 1.284 & 7.782 & 2566 & 2.880 \\
\hline 243 & 4.214 & 8.399 & 6.593 & 1.180 & 5.843 & 2.854 & 3.077 \\
\hline 244 & 4.146 & 8.334 & 4.802 & 1.150 & 5.404 & 2.864 & 2.771 \\
\hline 245 & 4.778 & 9.281 & 7.215 & 0.945 & 7.377 & 2.613 & 3407 \\
\hline 249 & 4.785 & 9150 & 0.866 & -1.250 & 6.179 & 4.339 & 3.418 \\
\hline 251 & 3.866 & 7.635 & 5.630 & 1.070 & 4.374 & 2.714 & 3.018 \\
\hline 252 & 3.940 & 7.391 & 4.400 & 1.492 & 3.664 & 2.729 & 2.337 \\
\hline 253 & 3.566 & 8.260 & 3.122 & 1.028 & 5.182 & 3.102 & 2.445 \\
\hline 254 & 3.623 & 7.293 & 5.660 & 1.121 & 3.990 & 2.953 & 2.974 \\
\hline 255 & 4.316 & 7.746 & 5.263 & 0.851 & 4.191 & 2.445 & 3.166 \\
\hline 256 & 3.854 & 7.627 & 5.555 & 1.068 & 4.255 & 2.785 & 3.006 \\
\hline 257 & 3.184 & 6.910 & 3118 & 0.763 & 5.939 & 3.666 & 2.708 \\
\hline 260 & 4.847 & 7.826 & 6.621 & 1153 & 5.580 & 1.994 & 3.109 \\
\hline 261 & 4.591 & 8839 & 11.890 & 1.252 & 6.323 & 2.272 & 3.653 \\
\hline 262 & 4.361 & 8.780 & 7.269 & 0.917 & 6.738 & 2.494 & 3.445 \\
\hline 263 & 4.159 & 8.864 & 4.028 & 0.872 & 6.616 & 2.823 & 2.865 \\
\hline 264 & 4.729 & 8.048 & 7.630 & 0.781 & 5.987 & 2.308 & 3.633 \\
\hline 265 & 4.635 & 9.941 & 8.143 & 1.015 & 8.473 & 2.403 & 3.469 \\
\hline 266 & 4.492 & 9.012 & 9.629 & 1.644 & 6.636 & 2.4197 & 3.025 \\
\hline 267 & 6.265 & 5.480 & 3.666 & 0.532 & 4.351 & 3.166 & 3.107 \\
\hline 268 & 4.364 & 8.327 & 6430 & 1.284 & 6.464 & 2.509 & 2.946 \\
\hline 269 & 5.381 & 9053 & 8859 & 1.035 & 7.1932 & 1.802 & 3.542 \\
\hline 271 & 5.011 & 8.047 & 6.894 & 0.973 & 4.202 & 1.889 & 3.332 \\
\hline 272 & 4.779 & 8.208 & 5.009 & 1.138 & 5.514 & 2.062 & 2.827 \\
\hline $273^{(2)}$ & 4.870 & 10.471 & 15.068 & 0.751 & 9.169 & 2607 & 4.428 \\
\hline 274 & 4.172 & 8.412 & 9.420 & 1.119 & 6.324 & 2.927 & 3.525 \\
\hline 275 & 3.163 & 6.176 & & & 3.469 & 3.336 & - \\
\hline 281 & 5.464 & 10444 & 21.363 & 1.507 & 7.254 & 1.845 & 4.097 \\
\hline $282^{(2)}$ & 5.328 & 10289 & 15.890 & 1.723 & 7.372 & 2.240 & 3158 \\
\hline 283 & 2.344 & 7.102 & 4.192 & 1.129 & 4.654 & 4.006 & 2.649 \\
\hline 291 & 4.672 & 8.920 & 18.444 & 0.681 & 5.564 & 2954 & 4.740 \\
\hline 292 & 6.469 & 9.557 & 8.264 & 0.938 & 4.400 & 0.682 & 3.562 \\
\hline 298 & 4.093 & 7.462 & 9.857 & 0.738 & 4.472 & 3.318 & 3.957 \\
\hline 299 & 4.542 & 7.731 & 10.754 & 0.593 & 4.442 & 3.125 & 4.099 \\
\hline 300 & 4.614 & 8.924 & 8.976 & - & 5.523 & 1.023 & 3.705 \\
\hline 301 & 4.869 & 15.657 & 1.234 & 5485 & 2.485 & 2.465 & 3.989 \\
\hline 302 & 4.583 & 8.902 & 22.395 & 1.377 & 6.151 & 2634 & 4.288 \\
\hline 303 & 3849 & 7.631 & 7.007 & 0.952 & 4.457 & 2914 & 3.370 \\
\hline 304 & 5.139 & 9.574 & 10153 & 1.319 & 5.879 & 1.853 & 3.408 \\
\hline 305 & 4206 & 7.902 & 10.753 & 1.136 & 4.864 & 2.580 & 3.656 \\
\hline 306 & 4.716 & 8.507 & 14.832 & 1.557 & 7.144 & 3116 & 3.603 \\
\hline 307 & 4.642 & 9.287 & 8.970 & 1.673 & 6.153 & 2.274 & 2.918 \\
\hline 308 & 3.922 & 7.195 & 6.145 & 0.995 & 5.492 & 2.991 & 3.186 \\
\hline 309 & 4.359 & 8.161 & 10.336 & 1.238 & 5.605 & 2.823 & 3.509 \\
\hline
\end{tabular}

Fonte: IBGE, tabulaçôes especiais Os dados brutos encontram-se com o autor; os interessados bastam solicitá-los

Obs (1) Os nümeros correspondem à codificação da indüstria, segundo a classificação do IBGE, a três dígitos. A respectiva denominação encontra-se em IBGE (1991)

(2) Setores pertencentes ao centro oligopolista

* LN representa o log natural da variável correspondente, definida no texto 
Tabela A.2 - Nordeste: Indicadores industriais - 1985

\begin{tabular}{|c|c|c|c|c|c|c|}
\hline $\begin{array}{l}\text { Setores da } \\
\text { Indústria }{ }^{(1)}\end{array}$ & $\operatorname{Ln}\left(Y_{i}\right)$ & $\overline{A_{j}}$ & $\operatorname{Ln}\left(W_{i 1} / W_{i 2}\right)$ & $\operatorname{Ln}\left(K_{i}\right)$ & $\operatorname{Ln}\left(P_{i}\right)$ & $\operatorname{Ln}\left(T_{i}\right)$ \\
\hline $001^{(2)}$ & 9.215 & 16.606 & 2.545 & 8.504 & 2994 & 3758 \\
\hline 002 & 7.979 & 14.799 & 1.985 & 5.856 & 2.526 & 3488 \\
\hline $003^{(2)}$ & 15.304 & 16.877 & 3818 & 12.114 & 1.430 & 4.555 \\
\hline 101 & 7287 & 7.667 & 20.43 & 5.129 & 2.676 & 3.505 \\
\hline 102 & 7.453 & 5.135 & 1.669 & 5.648 & 2.522 & 2.259 \\
\hline 104 & 9.148 & 7.654 & 1.557 & 7.883 & 3047 & 3. 191 \\
\hline $105^{(2)}$ & 10339 & 17.345 & 2.674 & 9.581 & 1.606 & 4.200 \\
\hline 106 & 7532 & 6.721 & 1.843 & 4.512 & 2498 & 2.720 \\
\hline $107^{(2)}$ & 9.915 & 11.681 & 2.020 & 8687 & 2516 & 4.052 \\
\hline 108 & 7.837 & 8.807 & 2.057 & 6.525 & 2.545 & 3.246 \\
\hline 109 & 7.745 & 15.317 & 2.270 & 6.856 & 3339 & 3.866 \\
\hline $110^{(2)}$ & 9.507 & 14.270 & 2.896 & 10.513 & 2.865 & 3.544 \\
\hline $111^{(2)}$ & 11.080 & 17.438 & 3.146 & 11.533 & 1.924 & 3.952 \\
\hline 112 & & & & & & \\
\hline 113 & 7.671 & 9.865 & 2.139 & 4.969 & 3095 & 3.358 \\
\hline 114 & 8.618 & 6.084 & 2228 & 6.244 & 2.317 & 3266 \\
\hline 115 & 7.616 & 10.279 & 2.060 & 5.408 & 3.042 & 3.311 \\
\hline 116 & 7.150 & 7684 & 1.625 & 4.612 & 2.317 & 3.212 \\
\hline 117 & 8.735 & 1.900 & 1.850 & 6.565 & 2.725 & 2.885 \\
\hline 118 & 6.977 & 6.211 & 2.502 & 5.056 & 3.039 & 3.124 \\
\hline 119 & 7.061 & 16.898 & 1.971 & 5.056 & 3.156 & 3.634 \\
\hline $121^{(2)}$ & 8430 & 7.511 & 2.381 & 4.845 & 2.903 & 3.194 \\
\hline 122 & 8.514 & 12.443 & 2.499 & 5387 & 2.787 & 3769 \\
\hline 123 & 9.200 & 8.357 & 3.073 & 7.171 & 2.984 & 4.038 \\
\hline 124 & 7359 & 3946 & 2069 & 3.624 & 2.509 & 2.795 \\
\hline 125 & 9.289 & 33005 & 1.897 & 5.817 & 2.017 & 4.719 \\
\hline 126 & 5887 & 0.000 & 2641 & - & 4.265 & " \\
\hline $127^{(2)}$ & 7.814 & 0.000 & 1551 & 1.879 & 1.808 & - \\
\hline 128 & 7.865 & 13.554 & 2.852 & 6.142 & 3.878 & 3.922 \\
\hline $129^{(2)}$ & & & & 8.901 & t & 4.175 \\
\hline 131 & 9.273 & 16.035 & 2.166 & 6.252 & 2755 & 4.190 \\
\hline 132 & 10.552 & 16.152 & 2.742 & 8936 & 1886 & 3940 \\
\hline 133 & 10.118 & 29050 & 2.480 & 6.858 & 2.223 & 4.395 \\
\hline 134 & 9.569 & 10.584 & 2484 & 8019 & 3.075 & 3.511 \\
\hline 135 & 6.779 & 7.424 & 1.637 & 4.223 & 2.759 & 4.181 \\
\hline 136 & 10.277 & 37.337 & 2.791 & 7.973 & 2.989 & 4.914 \\
\hline $137^{(2)}$ & 9.865 & 26.209 & 2.882 & 4.321 & 1390 & 4.407 \\
\hline $138^{(2)}$ & 9.690 & 35.334 & 2.869 & 2.282 & 1.548 & 4.576 \\
\hline 139 & 7420 & 17.612 & 3.199 & 4.463 & 3.455 & 4.796 \\
\hline 141 & 8.378 & 3889 & 1.444 & 5.042 & 1528 & 2.158 \\
\hline 142 & 8.579 & 2349 & 3.545 & 4.681 & 4.231 & 2.527 \\
\hline $143^{(2)}$ & 7.237 & 8303 & 1.862 & 4.902 & 2.783 & 3.351 \\
\hline 144 & 7.866 & 10.747 & 2.086 & 4.419 & 2.645 & 3.197 \\
\hline 145 & 9.855 & 5.311 & 2.355 & 8.418 & 3.016 & 4.369 \\
\hline 147 & 7.998 & & 1.994 & - & 1.737 & - \\
\hline 148 & 8.510 & 21.277 & 1.407 & 5.410 & 1818 & 2813 \\
\hline 149 & & & & & & \\
\hline 151 & 6319 & 3.685 & 1.502 & 4249 & 2697 & 2.859 \\
\hline 152 & 5652 & 1183 & 1.770 & 2.969 & 3.083 & 2.164 \\
\hline 153 & 7873 & 6.906 & 1.633 & 5478 & 2.976 & 2.592 \\
\hline 154 & & & & & & \\
\hline 155 & 5190 & 16.785 & 1.922 & 1849 & 3.426 & 5.167 \\
\hline 156 & & 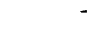 & & & & - \\
\hline 157 & - & - & - & - & - & - \\
\hline
\end{tabular}


Tabela A 2 - Nordeste: Indicadores industriais - 1985

\begin{tabular}{|c|c|c|c|c|c|c|}
\hline $\begin{array}{l}\text { Setores da } \\
\text { Indüstria }^{(1)}\end{array}$ & $\operatorname{Ln}\left(Y_{i}\right)$ & $\overline{A_{i}}$ & $\operatorname{Ln}\left(W_{i 1} / W_{i 2}\right)$ & $\operatorname{Ln}\left(K_{i}\right)$ & $\operatorname{Ln}\left(P_{i}\right)$ & $\ln \left(\bar{T}_{i}\right)$ \\
\hline 158 & $7: 256$ & & 2.152 & 2.094 & 2.471 & - \\
\hline 161 & 6521 & 3.580 & 1.699 & 3.942 & 2.952 & 2.869 \\
\hline 162 & 7.471 & 9.427 & 2.192 & 4.543 & 3.138 & 3.119 \\
\hline 163 & 5.347 & & 0.971 & & 2.937 & - \\
\hline 164 & 8.581 & 1.593 & 2. 187 & 5.022 & 2.447 & 1.746 \\
\hline 169 & 6.514 & 1.996 & 2.837 & 0.476 & 3.300 & 3.817 \\
\hline $171^{(2)}$ & 8765 & 4154 & 2587 & 8.816 & 3.120 & 2.184 \\
\hline $172^{(2)}$ & 8.417 & 6.997 & 2198 & 8.604 & 2.737 & 3.379 \\
\hline 173 & 8186 & 6.610 & 2290 & 5.580 & 2.542 & 2.784 \\
\hline 174 & 8.909 & 6.948 & 2.033 & 6.100 & 1.921 & 2.813 \\
\hline $175^{(2)}$ & 5.316 & 16.216 & 1.999 & 2.924 & & 3.147 \\
\hline 179 & & & & & & \\
\hline $181^{(2)}$ & 8568 & 17.001 & 2.333 & 5.261 & 1.827 & 4.086 \\
\hline $182^{(2)}$ & 7.353 & 17.060 & 2.200 & 4.931 & 2.376 & 4290 \\
\hline 183 & 7.692 & 0.615 & 1.788 & 6.127 & 3.052 & 1174 \\
\hline 184 & & & & & & - \\
\hline 185 & 8.168 & 7.641 & 1.947 & 6609 & 2.803 & 2.998 \\
\hline 189 & & & - & & & 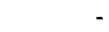 \\
\hline 191 & 8926 & 9.820 & 1.817 & 6.122 & 1.983 & 3.471 \\
\hline 192 & & & - & & & - \\
\hline 193 & 6.529 & . & 1.415 & 5.010 & 3.317 & - \\
\hline 199 & 6.767 & & 1.612 & 4.520 & 2.916 & - \\
\hline $200^{(2)}$ & 9.765 & 20.798 & 2.365 & 8.722 & 2.143 & 3.821 \\
\hline $201^{(2)}$ & 11.862 & 20.177 & 3.915 & 11.073 & 1.742 & 4.660 \\
\hline $202^{(2)}$ & 11.125 & 2.129 & 5.875 & 9953 & 4.103 & 4. 382 \\
\hline 203 & 9524 & 7.658 & 2180 & 6.127 & 2499 & 3.690 \\
\hline $205^{(2)}$ & 5.435 & & 1.219 & 1.235 & 1.998 & \\
\hline $206^{(2)}$ & 9.362 & 19.042 & 2.664 & 3.277 & 1.746 & 3.365 \\
\hline $207^{(2)}$ & 9.346 & 13.948 & 2.654 & 6359 & 1.813 & 3.674 \\
\hline $208^{(2)}$ & 9.291 & 8.784 & 2.494 & 5.525 & 1.435 & 3.573 \\
\hline $209^{(2)}$ & 8948 & 17.178 & 2.478 & 3.306 & 2.104 & 3.972 \\
\hline $211^{(2)}$ & 8.232 & 12.410 & - & 5.076 & 2.359 & 4.474 \\
\hline 221 & 8958 & 12771 & 1.976 & 5.897 & 1.522 & 2.914 \\
\hline 222 & 8.024 & 4.199 & 1935 & 5.072 & 1.798 & 2.841 \\
\hline 223 & 6576 & 2371 & 1.729 & 3427 & 2.487 & 2.347 \\
\hline 231 & 9.357 & 10.112 & 2.807 & 7.156 & 2.423 & 3645 \\
\hline 232 & 6.760 & 5.160 & 1.832 & 4.061 & 2.787 & 3.561 \\
\hline 233 & 9.387 & 8.800 & 2.263 & 7.138 & 2.114 & 3.448 \\
\hline 235 & 7.787 & 10.233 & 1.723 & 6.226 & 2.827 & 3.488 \\
\hline 236 & 9.746 & 14.060 & 2.150 & 7384 & 1.852 & 3.726 \\
\hline 237 & & & & & & \\
\hline 239 & 8682 & 6.941 & 1.849 & 6.098 & 2.246 & 3.155 \\
\hline 241 & 8148 & 6041 & 1.623 & 5.331 & 1.730 & 2.861 \\
\hline 242 & 9.927 & 4.736 & 2.076 & 8.561 & 2.348 & 2.596 \\
\hline 243 & 10.111 & 7.631 & 2.231 & 8.180 & 1426 & 3.054 \\
\hline 244 & 8.116 & 10.947 & 1.857 & 4.121 & 3269 & 3.367 \\
\hline 245 & 12.360 & 0.783 & 10.892 & 1.875 & 1.875 & 3.125 \\
\hline 249 & 8.121 & 3.195 & 1.844 & 5.911 & 2.211 & 2.236 \\
\hline 251 & 8.504 & 10.702 & 1.607 & 4.950 & 2402 & 3.210 \\
\hline 252 & 5431 & 0.000 & 1.545 & 2354 & 3.082 & - \\
\hline 253 & 8.474 & 1500 & 1.736 & 5.851 & 2.303 & 2.028 \\
\hline 254 & 6.114 & 0.000 & 1.933 & 3.504 & 3.608 & \\
\hline 255 & 7389 & 7419 & 1.938 & 4.919 & 2.827 & 3.094 \\
\hline 256 & 7.743 & 1.773 & 1.678 & 4.305 & 2.563 & 1.966 \\
\hline
\end{tabular}


Tabela A.2 - Nordeste: Indicadores industriais - 1985

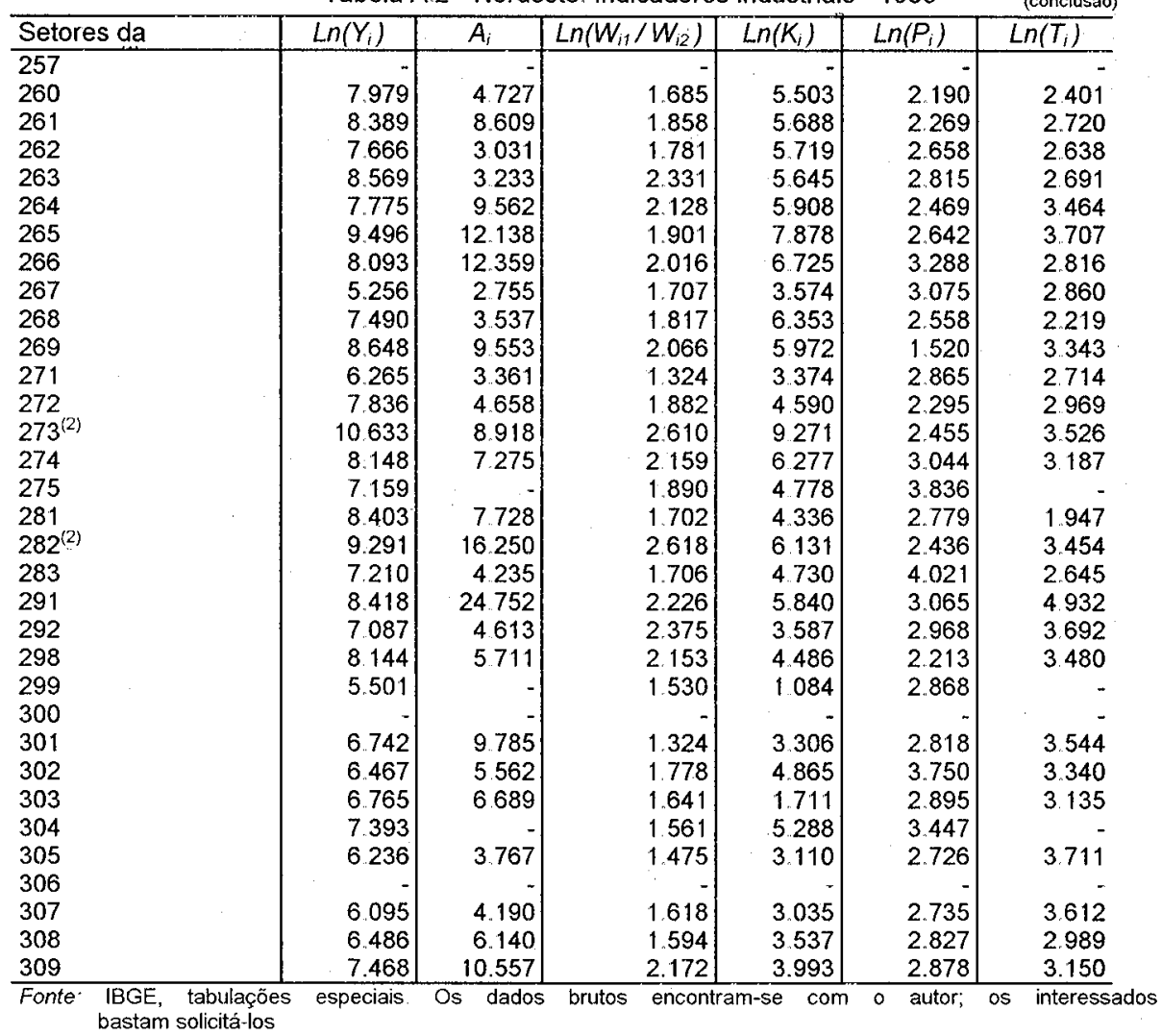

Obs: (1) Os nu̇meros correspondem à codificação da indústria, segundo a classificação do IBGE, a três dígitos A respectiva denominaçäo encontra-se em IBGE (1991)

(2) Setores pertencentes ao centro oligopolista

* LN representa o log natural da variável correspondente, definida no texto 


\section{BIBLIOGRAFIA}

AMADEO, Edward, CAMARGO, J. Marcio. Relaçס̃es entre capital e trabalho no Brasil percepção a atuação dos atores sociais, Rio de Janeiro: PUC/Depto. de Economia, 1990. (Texto para Discussão n. 243).

AMADEO, Edward, PEREIRA, Pedro Valls. Produtividade, custo do trabalho e parcela salarial nos ciclos recentes (1976-1985) Rio de Janeiro: IPE: PNPE, Cadernos de economia, n.3, 1990.

BARBOSA, F. Holanda. Microeconomia teoria, modelos econométricos e aplicações à economia brasileira. Rio de Janeiro: IPEA/INPES, 1985.

BARTEL, A. P. LICHENBERG, F. The comparative advantage of educated workers in implementing new technology. The Review of Economics and Statistics, V.LXIX, n.910, p.1-11, 1987.

BONELLI, R, RAMOS, L. Distribuição de renda no Brasil: avaliação das tendências de longo prazo e mudanças na desigualdade desde meados dos anos 70. Rio de Janeiro: IPEA, 1993. (Texto para Discussão n 288)

CAMARGO, J Márcio, GIAMBIAGI, Fábio (org.) Distribuiçăo de renda no Brasil. Rio de Janeiro: Paz e Terra, 1991.

GOLDBERGER, Arthur. Econometric theory. New York: John Wiley \& Sons, Inc, 1964.

GUIMARÃES NETO, L. Introdução à formaçăo económica do nordeste Recife:Massangana, 1989.

HAWORTH, $C$, REUTHER, $c$. Industrial concentration and interindustry wage determination. The Review of Economics and Statistics. V.LX, n 1; p. 85-95; fevereiro, 1978.

IBGE. Classificação de atividades e produfos, matérias-primas e serviços industriais. Rio de Janeiro: FIBGE, 1991

KALLEBERG, Arne L., WALLACE, Michael e RAFFALOVICH, Lawrence. Accouting for labor's share: class and income distribution in the priting industry. Ind and Labor Rel Rev.. v. 37, n. 3, abril, p. 386-402, 1984.

LANGONI, C Distribuição de renda e desenvolvimento económico do Brasil. Rio de Janeiro: Expansão e Cultura, 1973

LANZANA, A Evaristo T. Diferenciais de salários na economia brasileira: uma análise do periodo 1963-83. São Paulo: IPE/USP, 1987.

MACEDO, R. B Salários em Teoria Económica. Rio de Janeiro: IPEA/INPES, 1982.

MARINHO, Emerson L. Transferencia de renda dos trabalhadores do setor competitivo para os outros do setor oligopolizado: uma realidade no Brasil. Rio de Janeiro: Editora da Fundação Getülio Vargas, Série Teses EPGE N. 24, 1993.

PINHEIRO, A. Castelar. Measuring and explaining total factor productivity growth: brazilian manufacturing in the seveties. Rio de Janeiro: IPEA/INPES. (Textos para discussão n. 189, 1990)

ROSA, Antonio Lisboa $T$ da Formação e diferenciaçðes intersetoriais e inter-regionais da produtividade, dos salários e do excedente o caso da indüstria nordestina no contexto nacional. Recife: PIMES/UFPE, tese de doutorado,_1992

Segmentação da indüstria e estratificação dos trabalhadores no processo de distribuição da renda do trabalho no Brasil. Belo Horizonte: ANPEC, Anais do XXI encontro nacional de economia, vol 2, p. 647-666, 1993

SABÓlA, J. Salários e produtividade na indústria brasileira: os efeitos da política salarial a longo prazo. Rio de Janeiro: IPEA. Pesquisa e Planejamento Económico, v 20, n.3, dezembro, p. 581 . $599,1990$.

SAVEDOFF, William D. Wage dynamics in urban Brazil evidence of regional segmentation or national markets? Revista de Econometria n. 2, novembro, p 161-84, 1991

SILVEIRA, J D et alii. Estrutura industrial, emprego e produtividade na indústria de transformação cearense no periodo: 1960-80 Fortaleza: IPLANCE/CAEN, 1983.

SOUZA, Paulo Renato. Emprego, salarios e pobreza. São Paulo: Hucitec, 1980. 


\section{ABSTRACT}

The main interest of this paper is to analyse the factors affecting worker's income distribution in Brazilian in one of its regions, the Northeast. Data is basead on a cross sectional study where observational units are 141 different branches of industry, at a three digits disaggregation In spite of its static nature the results of the analysis ane nobust enough to give support to the view that worer's income concentration is explained by labour market segmentation, tecnical and estructural diferences among contracting firms, and diferences in labour union's power. Compared to the country the Northeast presents a lower level of concentration. However, mean wage is lower to all labour categories than in the country as a whole. From this can be concluded that low concentration, per se, is not a great advantage. Moreover, estimated demand for labour show that there is a latent potential for income concentration in Northeast's labour market. This is explained by the small number of vacancies and the low level of training required for opening jobs. 